\title{
Novel GATA4 mutations in lone atrial fibrillation
}

\author{
JIN-QI JIANG ${ }^{1}$, FANG-FANG SHEN $^{1}$, WEI-YI FANG ${ }^{2}$, XU LIU $^{2}$ and YI-QING YANG ${ }^{3}$ \\ Departments of ${ }^{1}$ Emergency, ${ }^{2}$ Cardiology and ${ }^{3}$ Cardiovascular Research, Shanghai Chest Hospital, \\ Medical College of Shanghai Jiaotong University, Shanghai 200030, P.R. China
}

Received June 25, 2011; Accepted August 10, 2011

DOI: $10.3892 / \mathrm{ijmm} .2011 .783$

\begin{abstract}
Atrial fibrillation (AF) is the most frequent cardiac arrhythmia and is a major cause of morbidity and mortality. Previous studies have established genetic defects as a risk factor for AF in a minority of patients. However, AF is of substantial genetic heterogeneity and the molecular determinants for AF in a majority of cases remain unclear. In this study, the entire coding sequence and splice junctions of GATA4, which encodes a zinc-finger transcription factor essential for cardiogenesis, were sequenced in 160 unrelated patients with lone AF. A total of 200 unrelated ethnically matched healthy individuals were used as controls. The available relatives of the patient carrying an identified mutation were genotyped. The functional characteristics of the mutant GATA4 were analyzed using a luciferase reporter assay system. As a result, two novel heterozygous GATA4 mutations of p.G16C and p.H28D, were identified in 2 unrelated families with AF, respectively, which co-segregated with AF in each family with complete penetrance. Functional analysis demonstrated that the mutations of GATA4 were associated with a significantly decreased transcriptional activity. The findings expand the mutation spectrum of GATA4 linked to AF and provide novel insight into the molecular mechanism involved in the pathogenesis of AF.
\end{abstract}

\section{Introduction}

Atrial fibrillation (AF) is the most common type of cardiac arrhythmia in the clinical setting. In the general population, the prevalence of AF is approximately $1 \%$, and increases with age to almost $10 \%$ in octogenarians (1). For subjects over 40 years of age, the estimated lifetime risk of developing AF is about $25 \%$ (2). This condition is responsible for substantial mortality and morbidity. Compared with individuals in normal rhythm, patients with AF have a six-fold increased risk of

Correspondence to: Dr Yi-Qing Yang, Department of Cardiovascular Research, Shanghai Chest Hospital, Medical College of Shanghai Jiaotong University, 241 West Huaihai Road, Shanghai 200030, P.R. China

E-mail: yang99yang66@hotmail.com

Key words: atrial fibrillation, transcription factor, genetics stroke and a 2-fold increased risk of death $(3,4)$. Traditionally, AF has been ascribed to various cardiac and systemic disorders that result in the electrical and structural remodeling of the atria and hence predispose atria to fibrillate, including coronary artery disease, rheumatic heart disease, myocarditis, pericarditis, cardiomyopathy, congenital heart defects, cardiac surgery, congestive heart failure, pulmonary embolism, type 2 diabetes, hypertension, hyperthyroidism, electrolyte imbalance, and even dyslipidemia $(5,6)$. However, in 30 to $45 \%$ of the patients, AF occurs in the absence of structural cardiovascular diseases and systemic abnormalities (5), and growing epidemiological studies substantiate the familial aggregation of AF and a significantly increased risk of AF in the close relatives of patients with AF, strongly suggesting a genetic basis for the disease (7-13). Furthermore, loci on chromosomes 10q2224, 6q14-16 and 5p13 have been linked to AF (14-16), and AF-associated mutations in multiple genes, including $K C N Q 1$, KCNE2, SCN5A, KCNH2, KCNJ2, GJA5, KCNA5, KCNE3, KCNE5, NPPA, NUP155, SCN1B, SCN2B, SCN3B, and GJA1 have been identified (17-31). Nevertheless, AF is a genetically heterogeneous disorder and the genetic determinants for AF in a majority of cases remain to be identified (32).

Recent studies have demonstrated the pivotal role for several cardiac transcription factors, including GATA4, in cardiogenesis (33-37). The human GATA4 gene maps to chromosome 8p23.1-p22 and constitutively consists of 7 exons, encoding a zinc-finger transcription factor, a protein of 442 amino acids (38). The transcription factor GATA4 is expressed throughout cardiac morphogenesis and is essential for normal cardiac development (39-41). Mutations in the GATA4 gene have been identified in patients with a wide variety of congenital cardiovascular anomalies including cardiac septal defect, tetralogy of Fallot, endocardial cushion defect, patent ductus arteriosus, pulmonary stenosis, and hypoplastic right ventricle (42-47). Interestingly, GATA4 mutations have also been observed in patients with lone $\mathrm{AF}$, implying a common genetic origin of AF with congenital cardiac malformations, although the functional effect of the mutations has not been characterized (48).

To evaluate the prevalence and spectrum of GATA4 mutations in a cohort of 160 patients with lone AF and investigate the mechanism by which mutated GATA4 contributes to AF, the coding exons and exon/intron boundaries of GATA4 were sequenced and the functional characteristics of the mutant GATA4 were analyzed in contrast to its wild-type counterpart using a luciferase reporter assay system. 
Table I. The intronic primers to amplify the coding exons and exon-intron boundaries of GATA4.

\begin{tabular}{lllc}
\hline Exon & \multicolumn{1}{c}{ Forward primer (5' to 3') } & \multicolumn{1}{c}{ Reverse primer (5' to 3') } & Amplicon size (bp) \\
\hline 2-a & GAT CTT CGC GAC AGT TCC TC & GTC CCC GGG AAG GAG AAG & 458 \\
$2-\mathrm{b}$ & GCT GGG CCT GTC CTA CCT & AAA AAC AAG AGG CCC TCG AC & 554 \\
3 & GGG CTG AAG TCA GAG TGA GG & GAT GCA CAC CCT CAA GTT CC & 437 \\
4 & GAG ATC TCA TGC AGG GTC GT & GCC CCT TCC AAA TCT AAG TC & 390 \\
5 & TCT TTC TCG CTG AGT TCC AG & GGG ATG TCC GAT GCT GTC & 379 \\
6 & GCC ATC CCT GTG AGA ACT GT & GAG GGT AGC TCA CTG CTT GC & 444 \\
7 & AAG TGC TCC TTG GTC CCT TC & TTC CCC TAA CCA GAT TGT CG & 479 \\
\hline
\end{tabular}

\section{Materials and methods}

Study participants. A total of 160 unrelated patients with lone AF were identified among the Han Chinese population. The controls were 200 ethnically matched unrelated healthy individuals. Peripheral venous blood specimens were prepared and clinical data including medical records, electrocardiogram and echocardiography reports were collected. The study subjects were clinically classified using a consistently applied set of definitions (32). Briefly, diagnosis of AF was made by a standard 12-lead electrocardiogram demonstrating no $\mathrm{P}$ waves and irregular R-R intervals regardless of clinical symptoms. Lone AF was defined as AF occurring in individuals $<60$ years of age without other cardiac or systemic diseases by physical examination, electrocardiogram, transthoracic echocardiogram, and extensive laboratory tests. Relatives with AF occurring at any age in the setting of structural heart disease (hypertensive, ischemic, myocardial or valvular, but not congenital) were classified as 'undetermined' for having an inherited form of AF. The 'undetermined' classification was also used if documentation of $\mathrm{AF}$ on an electrocardiogram tracing was lacking in relatives with symptoms consistent with $\mathrm{AF}$ (palpitations, dyspnea and light-headedness), or if a screening electrocardiogram and echocardiogram were not performed, irrespective of the symptoms. Relatives were classified as 'unaffected' if they were $\geq 18$ years of age, asymptomatic and had a normal electrocardiogram. Paroxysmal AF was defined as AF lasting more than $30 \mathrm{sec}$ that terminated spontaneously. Persistent $\mathrm{AF}$ was defined as AF lasting more than 7 days and requiring either pharmacologic therapy or electrical cardioversion for termination. AF that was refractory to cardioversion or that was allowed to continue was classified as permanent. The study protocol was reviewed and approved by the local institutional Ethics Committee and written informed consent was obtained from all participants prior to investigation.

Genetic studies. Genomic DNA from all participants was extracted from blood lymphocytes with the Wizard Genomic DNA Purification kit (Promega, Madison, WI, USA). Initially, the whole coding region and splice junctions of the GATA4 gene was screened in 160 unrelated patients with lone AF. Subsequently, genotyping GATA4 in the available relatives of the patients carrying identified mutations and 200 ethnically matched unrelated healthy control individuals was performed. The genomic DNA reference sequence of GATA4 was derived from GenBank (accession number: NC_000008). By the aid of the online Primer 3 software (http://frodo.wi.mit.edu), the primer pairs used to amplify the coding exons (exons 2-7) and intron-exon boundaries of GATA4 by polymerase chain reaction (PCR) were designed and are shown in Table I. The PCR was carried out using HotStarTaq DNA polymerase (Qiagen, Hilden, Germany) on a PE9700 Thermal Cycler (Applied Biosystems, Foster, CA, USA) with standard conditions and concentrations of reagents. Amplified products were purified with the QIAquick Gel Extraction kit (Qiagen). Both strands of each PCR product were sequenced with a BigDye ${ }^{\circledR}$ Terminator v3.1 Cycle Sequencing kit (Applied Biosystems) under an ABI PRISM 3130XL DNA Analyzer (Applied Biosystems). The sequencing primers were those designed previously for specific region amplifications. DNA sequences were viewed and analyzed with the DNA Sequencing Analysis Software v5.1 (Applied Biosystems). The variant was validated by resequencing of an independent PCR-generated amplicon from the subject and met our quality control thresholds with a call rate $>99 \%$.

Multiple sequence alignments. The multiple GATA4 protein sequences across various species were aligned using the MUSCLE program, version 3.6 (an online program at http:// www.ncbi.nlm.nih.gov/).

Plasmids and site-directed mutagenesis. The recombinant expression plasmids pSSRa-GATA4 and atrial natriuretic peptide-luciferase reporter gene, which contains the $2600 \mathrm{bp}$ 5'-flanking region of the atrial natriuretic peptide gene, namely ANP(-2600)-Luc, were kindly provided by Dr Ichiro Shiojima from Chiba University School of Medicine, Japan. The identified mutation was introduced into the wild-type GATA4 using a QuikChange II XL Site-Directed Mutagenesis kit (Stratagene, La Jolla, CA, USA) with a complementary pair of primers. The mutant was sequenced to confirm the desired mutation and to exclude any other sequence variations.

Reporter gene assays. COS-7 cells were cultured in Dulbecco's modified Eagle's medium supplemented with $10 \%$ fetal calf serum. The ANP(-2600)-Luc reporter construct and an internal control reporter plasmid pGL4.75 (hRluc/CMV, Promega) were used in transient transfection assays to examine the transcriptional activation function of the GATA4 mutant. COS-7 cells were transfected with $0.2 \mu \mathrm{g}$ of wild-type or mutant pSSRaGATA4 expression vector, $0.2 \mu \mathrm{g}$ of ANP(-2600)-Luc reporter construct, and $0.04 \mu \mathrm{g}$ of pGL 4.75 control reporter vector using 
Table II. The baseline clinical characteristics of the 160 unrelated patients with lone atrial fibrillation (AF).

\begin{tabular}{|c|c|c|}
\hline Features & Number or quantity & Percentage or range \\
\hline Male/female & $100 / 60$ & $63 / 38$ \\
\hline Age at first diagnosis of AF (years) & 46.39 & $26-58$ \\
\hline \multicolumn{3}{|l|}{ Type of AF at presentation } \\
\hline Paroxysmal & 120 & 75 \\
\hline Persistent & 29 & 18 \\
\hline Permanent & 11 & 7 \\
\hline Positive family history of AF & 32 & 20 \\
\hline History of cardioversion & 46 & 29 \\
\hline History of pacemaker & 6 & 4 \\
\hline Resting heart rate (bpm) & 73.13 & $56-172$ \\
\hline Systolic blood pressure (mmHg) & 124.77 & $92-136$ \\
\hline Diastolic blood pressure (mmHg) & 82.16 & $62-88$ \\
\hline Body mass index $\left(\mathrm{kg} / \mathrm{m}^{2}\right)$ & 22.93 & $21-25$ \\
\hline Left atrial diameter (mm) & 37.84 & $31-50$ \\
\hline Left ventricular ejection fraction $(\%)$ & 65 & $54-75$ \\
\hline Fasting blood glucose (mmol/l) & 4.38 & $4-6$ \\
\hline Total cholesterol (mmol/l) & 3.80 & $3-5$ \\
\hline Triglycerides (mmol/l) & 1.26 & $1-2$ \\
\hline \multicolumn{3}{|l|}{ Medications } \\
\hline Aspirin & 56 & 35 \\
\hline Warfarin & 35 & 22 \\
\hline$\beta$-blocker & 42 & 26 \\
\hline Calcium channel blocker & 24 & 15 \\
\hline Digoxin & 48 & 30 \\
\hline
\end{tabular}

the PolyFect Transfection Reagent (Qiagen). For co-transfection experiments, $0.1 \mu \mathrm{g}$ of wild-type pSSRa-GATA4, $0.1 \mu \mathrm{g}$ of mutant pSSRa-GATA4, $0.2 \mu \mathrm{g}$ of ANP(-2600)-Luc, and $0.04 \mu \mathrm{g}$ of pGL4.75 were used. Firefly luciferase and Renilla luciferase activities were measured with the Dual-Glo luciferase assay system (Promega) $48 \mathrm{~h}$ after transfection. Three independent experiments were performed at a minimum for wild-type and mutant GATA4.

Statistical analysis. Data are expressed as means \pm SD. Continuous variables were tested for normality of distribution and the Student's unpaired t-test was used for comparison of numeric variables between two groups. Comparison of the categorical variables between two groups was performed using the Pearson's $\chi^{2}$ test or the Fisher's exact test when appropriate. A 2-tailed $\mathrm{P}$-value $<0.05$ was considered to be statistically significant.

\section{Results}

Characteristics of the study subjects. A cohort of 160 unrelated patients with lone AF was recruited and clinically evaluated in contrast to a total of 200 ethnically matched unrelated healthy individuals used as controls. None of them had overt traditional risk factors for AF. There were no significant differences between patient and control groups in baseline characteristics including age, gender, body mass index, blood pressure, fasting blood glucose, serum lipid, left atrial dimension, left ventricular ejection fraction, heart rate at rest, as well as life style. The baseline clinical characteristics of the 160 patients with lone AF are summarized in Table II.

GATA4 mutations. Direct sequencing of the GATA4 gene was conducted after PCR amplification of genomic DNA from the 160 unrelated patients. Two heterozygous missense mutations in GATA4 were identified in 2 out of 160 patients, respectively. The total population prevalence of the GATA4 mutations was $1.25 \%$. A substitution of $\mathrm{T}$ for $\mathrm{G}$ in the first nucleotide of codon $16(\mathrm{c} .46 \mathrm{G}>\mathrm{T})$, predicting the transition of glycine $(\mathrm{G})$ into cysteine (C) at amino acid 16 (p.G16C) was detected in the patient from family 1 . The mutation c. $82 \mathrm{C}>\mathrm{G}$, corresponding to the mutation p.H28D, was found in the patient from family 2 . The sequence chromatograms showing the observed heterozygous GATA4 mutations of c. $46 \mathrm{G}>\mathrm{T}$ and c. $82 \mathrm{C}>\mathrm{G}$ compared with control sequences are shown in Fig. 1. A schematic diagram of GATA4 depicting the structural domains and locations of mutations identified in AF patients is presented in Fig. 2. The two newly identified mutations were not reported in the SNP database (http:// www.ncbi.nlm.nih.gov/SNP) and no mutations were found in the 200 control individuals by sequencing of the six coding 


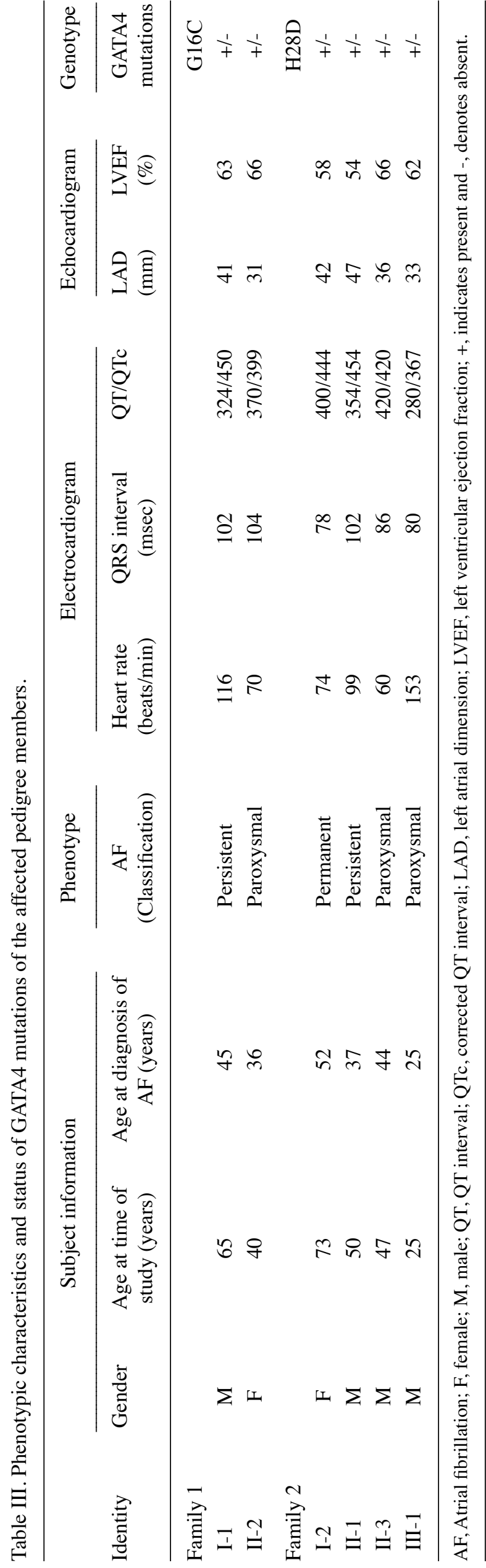

A C C GCCCCC GG TG C TAC GAG

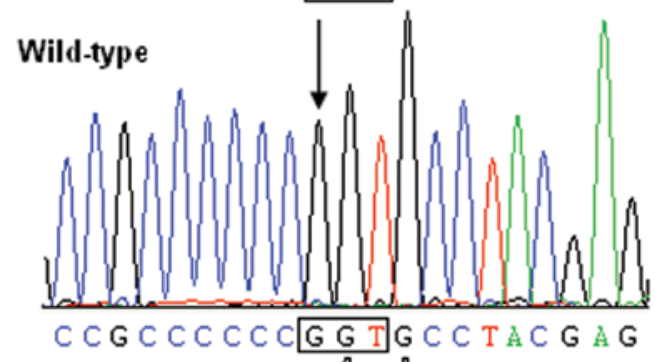

Mutant

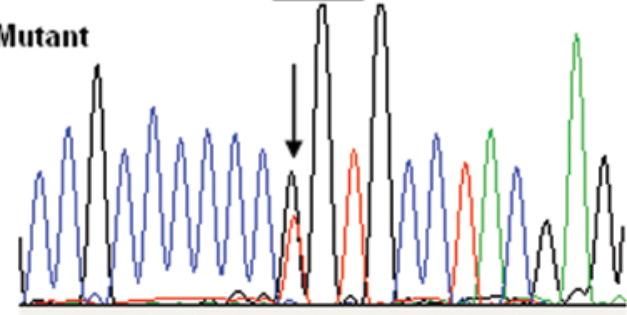

B
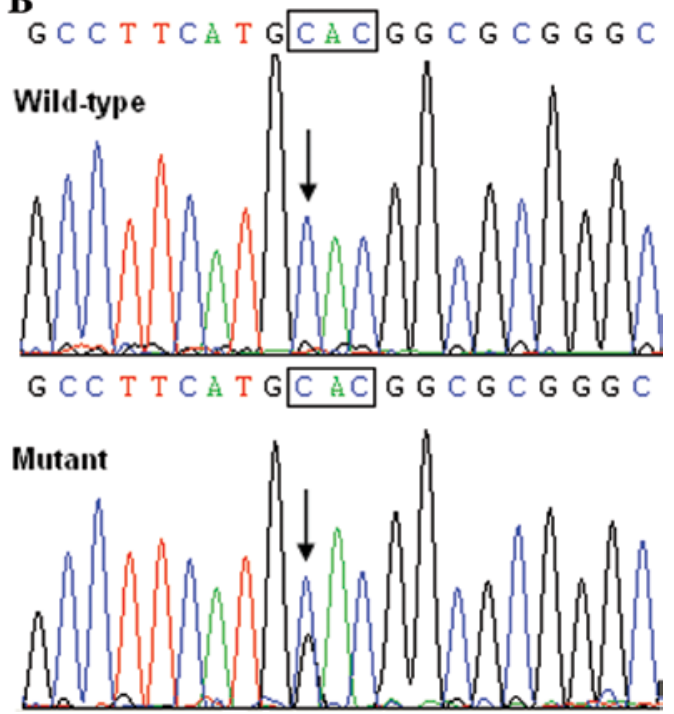

Figure 1. Sequence chromatograms of GATA4 in index patients and control subjects. The heterozygous GATA4 mutations of (A) c.46G>T and (B) c. $82 \mathrm{C}>\mathrm{G}$ compared with control sequences. The arrow indicates the heterozygous nucleotides of (A) $\mathrm{G} / \mathrm{T}$ and (B) $\mathrm{C} / \mathrm{G}$ in the probands from families 1 and 2 (mutant), respectively or the homozygous nucleotides of (A) G/G and (B) $\mathrm{C} / \mathrm{C}$ in the corresponding control individuals (wild-type). The square denotes the nucleotides comprising a codon of GATA4.

Figure 2. Diagram of GATA4 showing the locations of exonic germline mutations linked to atrial fibrillation. All mutations found in patients with atrial fibrillation are shown above the diagram of the GATA4 protein. The mutations evaluated by family are represented in bold letters and those also by functional analyses are marked with an asterisk. $\mathrm{NH}_{2}$, amino-terminus; TAD, transcriptional activation domain; ZF, zinc finger; NLS, nuclear localization signal; $\mathrm{COOH}$, carboxyl-terminus.

exons of GATA4. The genetic scan of the two unrelated families exhibited that in each family the mutation was present in all affected living family members, but absent in unaffected 

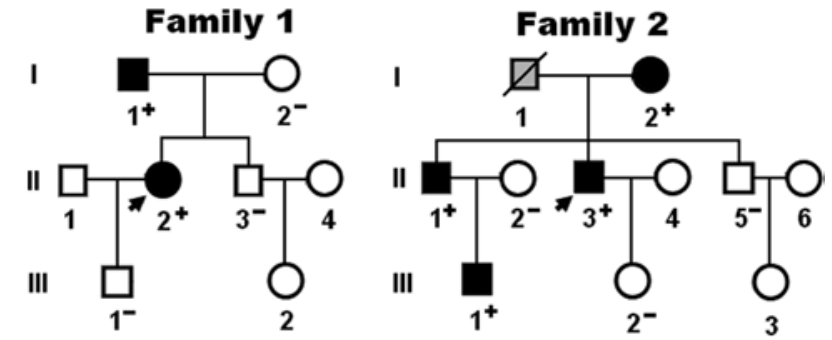

Figure 3. Pedigree structures of families with atrial fibrillation, designated as families 1 and 2, respectively. Family members are identified by generations and numbers; squares indicate male family members; circles, female members; symbols with a slash, the deceased members; closed symbols, affected members; open symbols, unaffected members; stippled symbols, members with phenotype undetermined; arrow, proband; +, carriers of the heterozygous mutation; and -, non-carriers.

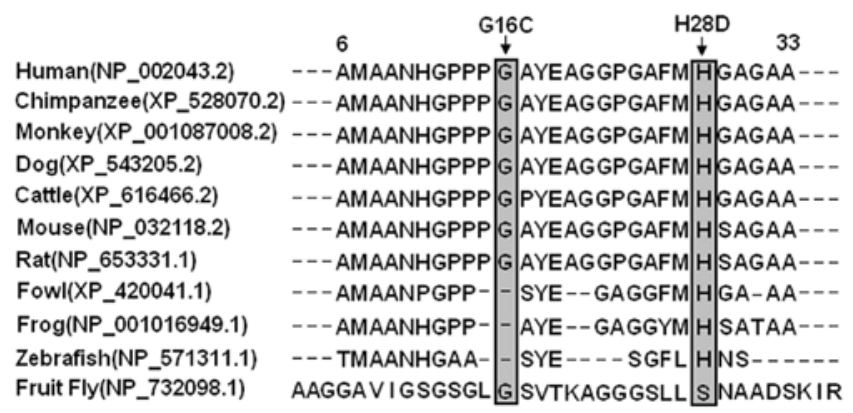

Figure 4. Alignment of multiple GATA4 protein sequences across species. The altered amino acids of G16 and $\mathrm{H} 28$ are highly conserved evolutionarily.

family members tested. Analysis of the pedigrees demonstrated that each mutation co-segregated with AF transmitted as an autosomal dominant trait in the family with a complete penetrance. The pedigree structures of the 2 families are illustrated in Fig. 3. The phenotypic characteristics and results of genetic screening of the affected family members are listed in Table III. Additionally, all the affected individuals harboring identified mutations presented with isolated AF and without evidence of echocardiogram documented cardiac deformities except for patient II-1 from family 2 , who had a catheter-based repair of congenital atrial septal defect at the age of 38 years. Since some congenital cardiac structural defects may close spontaneously, we cannot rule out the possibility that some of the mutation carriers had smaller cardiac septal defects that closed shortly after birth on their own.

Alignment of multiple GATA4 protein sequences across species. A cross-species alignment of GATA4 protein sequences showed that the altered amino acids were highly conserved evolutionarily, as presented in Fig. 4, suggesting that the amino acids are functionally important.

Transcriptional activity of the GATA4 mutants. The transcriptional activation characterization of the mutated GATA4 in COS-7 cells was explored using one of its direct cardiac downstream target genes, $A N P$, as a luciferase reporter, and the activity of the ANP promoter was presented as foldactivation of Firefly luciferase relative to Renilla luciferase.

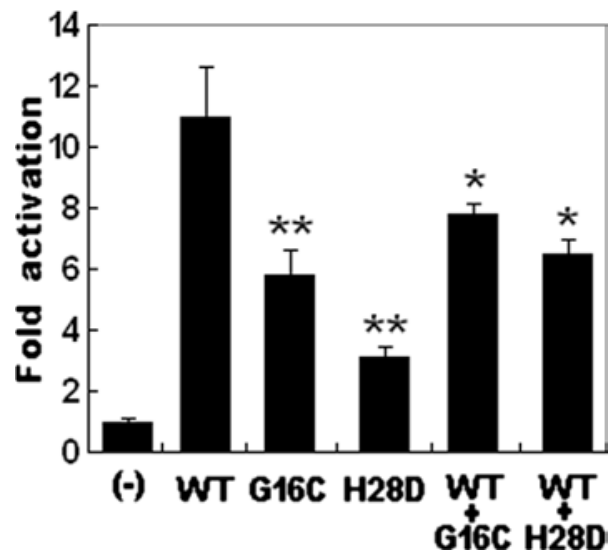

Figure 5. Transcriptional activity of the mutant GATA4 on the ANP promoter. COS-7 cells were transfected with $0.2 \mu \mathrm{g}$ of wild-type or mutant pSSRaGATA4 expression vector, $0.2 \mu \mathrm{g}$ of ANP(-2600)-Luc reporter construct, and $0.04 \mu \mathrm{g}$ of pGL4.75 control reporter vector. For co-transfection experiments, $0.1 \mu \mathrm{g}$ of wild-type pSSRa-GATA4, $0.1 \mu \mathrm{g}$ of mutant pSSRa-GATA4, $0.2 \mu \mathrm{g}$ of ANP(-2600)-Luc, and $0.04 \mu \mathrm{g}$ of pGL4.75 were used. The activity of the ANP promoter was presented as fold-activation of Firefly luciferase relative to Renilla luciferase. Values are the mean \pm SD of data from three independent experiments performed in triplicate. ${ }^{*} \mathrm{P}<0.05$ and ${ }^{* *} \mathrm{P}<0.01$, respectively, when compared with the wild-type GATA4.

The same amounts of wild-type $(0.2 \mu \mathrm{g})$, G16C-mutant, and H28D-mutant GATA4 $(0.2 \mu \mathrm{g})$ activated the ANP promoter by $\sim 11$-fold, $\sim 6$-fold, and $\sim 3$-fold, respectively. When the same amount of wild-type GATA4 $(0.1 \mu \mathrm{g})$ was co-transfected with G16C-mutant GATA4 $(0.1 \mu \mathrm{g})$, or with H28D-mutant GATA4 $(0.1 \mu \mathrm{g})$, the induced activation of the ANP promoter was $\sim 8$-fold or $\sim 6$-fold. These results suggest that each of the two GATA4 mutations has a significantly reduced activation activity compared with wild-type counterpart (Fig. 5).

\section{Discussion}

In the current study, two heterozygous missense GATA4 mutations of p.G16C and p.H28D identified in 2 out of 160 unrelated patients with lone AF are described. In each family, the previously unrecognized mutation of GATA4 co-segregated with $\mathrm{AF}$ and was absent in the 400 normal chromosomes from a matched control population. Multiple alignments of GATA4 protein sequences across species displayed that the mutations affected the amino acids which are highly conserved evolutionarily. Functional analysis demonstrated that the p.G16C and p.H28D mutations of GATA4 were consistently associated with a significantly decreased transcriptional activity. Therefore, the GATA4 mutations found in these two families may be responsible for AF. To our knowledge, this is the first description of the relationship between GATA4 loss-offunction mutation and susceptibility to lone AF.

GATA is a large family of transcription factors characterized by their ability to bind to the consensus DNA sequence 'GATA'. In vertebrates, six members of the GATA family have been identified, of which GATA4, GATA5 and GATA6 are expressed mainly in the developing heart (49). Functionally GATA4 comprises 2 transcriptional activation domains (TAD1, amino acids 1-74; TAD2, amino acids 130-177), 2 zinc finger domains (ZF1, amino acids 215-240; ZF2, amino acids 
270-294), and 1 nuclear localization signal (NLS, amino acids 254-324) (50). The two TADs are both essential for the transcriptional activity of GATA4. The C-terminal ZF1 is required for DNA sequence recognition and binding to the consensus motif, while the N-terminal ZF2 is responsible for sequence specificity and stability of protein-DNA binding. The NLS sequence is associated with the subcellular trafficking and distribution of GATA4. The GATA4 mutations of p.G16C and p.H28D are both located in TAD1, thus may be expected to exert direct influence on the transcriptional activity of GATA4.

Previous investigations have substantiated that GATA4 is an upstream regulator of several genes expressed during cardiac development including the ANP gene (49). GATA4 may bind to target DNA in conjunction with other partners including transcription factor TBX5 and NKX2-5, and the synergistic transcriptional activation mediated by TBX5 and NKX2-5 has been ascertained $(42,51)$. Hence, the functional characteristics of the GATA4 mutations may be characterized by analysis of the transcriptional activity of the ANP promoter. In this study, the functional effect of the novel p.G16C and p.H28D mutations of GATA4 were explored by transcriptional activity assays and the results displayed a significantly decreased transcriptional activity on a downstream gene, consistent with the loss-of function effects of other GATA4 mutations underlying congenital cardiovascular anomalies on the transcriptional activity of the ANP promoter $(42,51)$. These findings imply that haploinsufficiency resulting from GATA4 mutations is potentially an important pathophysiological mechanism involved in AF.

The fact that functionally compromised GATA4 predisposes to AF may be partially ascribed to the anomalous development of the pulmonary vein myocardium (51-53). The pulmonary venous vessels are ensheathed by a myocardial layer known as the pulmonary myocardial sleeve, which has been shown to be involved in the initiation and perpetuation of AF by several possible pathological mechanisms including intrinsic pacemaker activity and properties in favor of re-entrance $(54,55)$. Genetic-labeling lineage tracing studies have demonstrated that Nkx2-5 is expressed in all atrial and ventricular myocytes, atrioventricular conduction system, as well as pulmonary myocardium and is essential for embryonic development of the localized formation of the sinoatrial node. Nkx2-5 functions in dose-dependent manner as a repressor of the sinoatrial node lineage gene program, thus limiting pacemaker activity to the sinus node and the atrioventricular node. When the Nkx2-5 protein levels were low in a hypomorphic model, the pulmonary cardiomyocytes switched to connexin 40-negative, HCN4-positive cells, a pacemaker-like phenotype (52). In $N k \times 2-5$-null mouse embryos, $H C N 4$ was expressed in the entire embryonic heart tube, whereas connexin 40 expression was strongly reduced or absent and ectopic expression of pacemaker cells was observed throughout the heart tube (56). In humans, AF was reported as an isolated phenotype or a part of compound phenotype in patients harboring $N k \times 2-5$ mutations (57-59). Therefore, as a transcriptionally cooperative partner of $N k x 2-5, G A T A 4$, when a loss-of-function mutation occurs, may contribute to formation of the pulmonary myocardium sleeve and shift of the pulmonary myocardium to a pacemaker-like phenotype by reducing the level of $\mathrm{Nkx} 2-5$, hence providing an atrial electrophysiological substrate facilitating AF.
There is a great number of downstream genes activated by GATA4, and mutations in several target molecules have been associated with AF, including $\beta$ myosin heavy chain, atrial natriuretic peptide, and connexin $40(22,23,27,49,60)$. Therefore, mutated GATA4 likely confers susceptibility to AF by reducing expression of target genes.

It is interesting that a congenital atrial septal defect was observed in an AF patient carrying the p.H28D mutation of GATA4. Also, Posch et al (48) sequenced the entire coding region of GATA4 in 96 lone AF patients of Caucasian origin and identified a novel mutation of p.M247T and a previously reported mutation of p.A411V, with a mutation prevalence of $2.08 \%$. Similarly to our findings, atrial septal aneurysm was found in an AF patient carrying the p.M247T mutation and the AF-associated mutation of p.A411V was previously implicated in congenital septal defects and cardiac hypertrophy. These results indicate that AF may share a common genetic origin with congenital heart disease.

In conclusion, this study expands the mutation spectrum of GATA4 linked to AF and provides new insight into the molecular mechanism involved in the pathogenesis of AF, suggesting the potential implications in the genetic diagnosis and gene-specific therapy of this common arrhythmia.

\section{Acknowledgements}

We are indebted to the participants for their dedication to the study. This study was supported in part by grants from the Natural Science Fund of Shanghai, China (10ZR1428000), the Personnel Development Foundation of Shanghai, China (2010019), the Key Program of Basic Research of Shanghai, China (10JC1414000, 10JC1414001 and 10JC1414002), the National Natural Science Fund of China (81070153, 30871083 and 30570768), and the National Basic Research Program of China (2010CB912604).

\section{References}

1. Go AS, Hylek EM, Phillips KA, Chang Y, Henault LE, Selby JV and Singer DE: Prevalence of diagnosed atrial fibrillation in adults: national implications for rhythm management and stroke prevention: the AnTicoagulation and Risk Factors in Atrial Fibrillation (ATRIA) Study. JAMA 285: 2370-2375, 2001.

2. Lloyd-Jones DM, Wang TJ, Leip EP, Larson MG, Levy D, Vasan RS, D'Agostino RB, Massaro JM, Beiser A, Wolf PA and Benjamin EJ: Lifetime risk for development of atrial fibrillation: the Framingham Heart Study. Circulation 110: 1042-1046, 2004.

3. Wolf PA, Abbott RD and Kannel WB: Atrial fibrillation as an independent risk factor for stroke: the Framingham Study. Stroke 22: 983-988, 1991 .

4. Benjamin EJ, Wolf PA, D'Agostino RB, Silbershatz H, Kannel WB and Levy D: Impact of atrial fibrillation on the risk of death: the Framingham Heart Study. Circulation 98: 946-952, 1998.

5. Fuster V, Rydén LE, Cannom DS, Crijns HJ, Curtis AB, Ellenbogen KA, Halperin JL, Kay GN, Le Huezey JY, Lowe JE, Olsson SB, Prystowsky EN, Tamargo JL, Wann LS, Smith SC Jr, Priori SG, Estes NA III, Ezekowitz MD, Jackman WM, January CT, Lowe JE, Page RL, Slotwiner DJ, Stevenson WG, Tracy CM, Jacobs AK, Anderson JL, Albert N, Buller CE, Creager MA, Ettinger SM, Guyton RA, Halperin JL, Hochman JS, Kushner FG, Ohman EM, Stevenson WG, Tarkington LG, Yancy CW; American College of Cardiology Foundation/ American Heart Association Task Force: 2011 ACCF/AHA/HRS focused updates incorporated into the ACC/AHA/ESC 2006 guidelines for the management of patients with atrial fibrillation: a report of the American College of Cardiology Foundation/ American Heart Association Task Force on Practice Guidelines. Circulation 123: e269-e367, 2011. 
6. Kim SM, Lee JH, Kim JR, Shin DG, Lee SH and Cho KH: Female patients with atrial fibrillation have increased oxidized and glycated lipoprotein properties and lower apolipoprotein A-I expression in HDL. Int J Mol Med 27: 841-849, 2011.

7. Fox CS, Parise H, D'Agostino RB Sr, Lloyd-Jones DM, Vasan RS Wang TJ, Levy D, Wolf PA and Benjamin EJ: Parental atrial fibrillation as a risk factor for atrial fibrillation in offspring. JAMA 291: 2851-2855, 2004

8. Ellinor PT, Yoerger DM, Ruskin JN and MacRae CA: Familial aggregation in lone atrial fibrillation. Hum Genet 118: 179-184, 2005 .

9. Arnar DO, Thorvaldsson S, Manolio TA, Thorgeirsson G, Kristjansson K, Hakonarson H and Stefansson K: Familial aggregation of atrial fibrillation in Iceland. Eur Heart J 27: 708-712, 2006.

10. Junttila MJ, Raatikainen MJ, Perkiömäki JS, Hong K, Brugada R and Huikuri HV: Familial clustering of lone atrial fibrillation in patients with saddleback-type ST-segment elevation in right precordial leads. Eur Heart J 28: 463-468, 2007.

11. Christophersen IE, Ravn LS, Budtz-Joergensen E, Skytthe A, Haunsoe S, Svendsen JH and Christensen K: Familial aggregation of atrial fibrillation: a study in Danish twins. Circ Arrhythm Electrophysiol 2: 378-383, 2009.

12. Yang YQ, Zhang XL, Wang XH, Tan HW, Shi HF, Jiang WF Fang WY and Liu X: Familial aggregation of lone atrial fibrillation in the Chinese population. Intern Med 49: 2385-2391, 2010.

13. Lubitz SA, Yin X, Fontes JD, Magnani JW, Rienstra M, Pai M, Villalon ML, Vasan RS, Pencina MJ, Levy D, Larson MG, Ellinor PT and Benjamin EJ: Association between familial atria fibrillation and risk of new-onset atrial fibrillation. JAMA 304 2263-2269, 2010.

14. Brugada R, Tapscott T, Czernuszewicz GZ, Marian AJ, Iglesias A Mont L, Brugada J, Girona J, Domingo A, Bachinski LL and Roberts R: Identification of a genetic locus for familial atrial fibrillation. N Engl J Med 336: 905-911, 1997.

15. Ellinor PT, Shin JT, Moore RK, Yoerger DM and MacRae CA Locus for atrial fibrillation maps to chromosome 6q14-16. Circulation 107: 2880-2883, 2003

16. Oberti C, Wang L, Li L, Dong J, Rao S, Du W and Wang Q: Genome-wide linkage scan identifies a novel genetic locus on chromosome $5 \mathrm{p} 13$ for neonatal atrial fibrillation associated with sudden death and variable cardiomyopathy. Circulation 110 : 3753-3759, 2004.

17. Chen YH, Xu SJ, Bendahhou S, Wang XL, Wang Y, Xu WY, Jin HW, Sun H, Su XY, Zhuang QN, Yang YQ, Li YB, Liu Y, Xu HJ, Li XF, Ma N, Mou CP, Chen Z, Barhanin J and Huang W: KCNQ1 gain-of-function mutation in familial atrial fibrillation. Science 299: 251-254, 2003.

18. Yang Y, Xia M, Jin Q, Bendahhou S, Shi J, Chen Y, Liang B, Lin J, Liu Y, Liu B, Zhou Q, Zhang D, Wang R, Ma N, Su X, Niu K, Pei Y, Xu W, Chen Z, Wan H, Cui J, Barhanin J and Chen Y: Identification of a KCNE2 gain-of-function mutation in patients with familial atrial fibrillation. Am J Hum Genet 75: 899-905, 2004.

19. Olson TM, Michels VV, Ballew JD, Reyna SP, Karst ML, Herron KJ, Horton SC, Rodeheffer RJ and Anderson JL: Sodium channel mutations and susceptibility to heart failure and atrial fibrillation. JAMA 293: 447-454, 2005.

20. Hong K, Bjerregaard P, Gussak I and Brugada R: Short QT syndrome and atrial fibrillation caused by mutation in $\mathrm{KCNH} 2 . \mathrm{J}$ Cardiovasc Electrophysiol 16: 394-396, 2005.

21. Xia M, Jin Q, Bendahhou S, He Y, Larroque MM, Chen Y, Zhou Q, Yang Y, Liu Y, Liu B, Zhu Q, Zhou Y, Lin J, Liang B, Li L, Dong X, Pan Z, Wang R, Wan H, Qiu W, Xu W, Eurlings P, Barhanin J and Chen Y: A Kir2.1 gain-of-function mutation underlies familial atrial fibrillation. Biochem Biophys Res Commun 332: 1012-1019, 2005.

22. Gollob MH, Jones DL, Krahn AD, Danis L, Gong XQ, Shao Q, Liu X, Veinot JP, Tang AS, Stewart AF, Tesson F, Klein GJ, Yee R, Skanes AC, Guiraudon GM, Ebihara L and Bai D: Somatic mutations in the connexin 40 gene (GJA5) in atrial fibrillation. N Engl J Med 354: 2677-2688, 2006.

23. Yang YQ, Zhang XL, Wang XH, Tan HW, Shi HF, Jiang WF, Fang WY and Liu X: Connexin 40 nonsense mutation in familial atrial fibrillation. Int J Mol Med 26: 605-610, 2010.

24. Olson TM, Alekseev AE, Liu XK, Park S, Zingman LV, Bienengraeber M, Sattiraju S, Ballew JD, Jahangir A and Terzic A: Kv1.5 channelopathy due to KCNA5 loss-of-function mutation causes human atrial fibrillation. Hum Mol Genet 15: 2185-2191, 2006.
25. Lundby A, Ravn LS, Svendsen JH, Hauns S, Olesen SP and Schmitt N: KCNE3 mutation V17M identified in a patient with lone atrial fibrillation. Cell Physiol Biochem 21: 47-54, 2008.

26. Ravn LS, Aizawa Y, Pollevick GD, Hofman-Bang J, Cordeiro JM, Dixen U,Jensen G, Wu Y,Burashnikov E, Haunso S, Guerchic off A, $\mathrm{Hu}$ D, Svendsen JH, Christiansen M and Antzelevitch C: Gain of function in IKs secondary to a mutation in KCNE5 associated with atrial fibrillation. Heart Rhythm 5: 427-435, 2008.

27. Hodgson-Zingman DM, Karst ML, Zingman LV, Heublein DM, Darbar D, Herron KJ, Ballew JD, de Andrade M, Burnett JC Jr and Olson TM: Atrial natriuretic peptide frameshift mutation in familial atrial fibrillation. N Engl J Med 359: 158-165, 2008.

28. Zhang X, Chen S, Yoo S, Chakrabarti S, Zhang T, Ke T, Oberti C, Yong SL, Fang F, Li L, de la Fuente R, Wang L, Chen Q and Wang QK: Mutation in nuclear pore component NUP155 leads to atrial fibrillation and early sudden cardiac death. Cell 135: 1017-1027, 2008

29. Watanabe H, Darbar D, Kaiser DW, Jiramongkolchai K, Chopra S, Donahue BS, Kannankeril PJ and Roden DM: Mutations in sodium channel beta1- and beta2-subunits associated with atrial fibrillation. Circ Arrhythm Electrophysiol 2: 268-275, 2009.

30. Wang P, Yang Q, Wu X, Yang Y, Shi L, Wang C, Wu G, Xia Y, Yang B, Zhang R, Xu C, Cheng X, Li S, Zhao Y, Fu F, Liao Y, Fang F, Chen Q, Tu X and Wang QK: Functional dominant-negative mutation of sodium channel subunit gene SCN3B associated with atrial fibrillation in a Chinese GeneID population. Biochem Biophys Res Commun 398: 98-104, 2010.

31. Thibodeau IL, Xu J, Li Q, Liu G, Lam K, Veinot JP, Birnie DH, Jones DL, Krahn AD, Lemery R, Nicholson BJ and Gollob MH: Paradigm of genetic mosaicism and lone atrial fibrillation: physiological characterization of a connexin 43-deletion mutant identified from atrial tissue. Circulation 122: 236-244, 2010.

32. Darbar D, Herron KJ, Ballew JD, Jahangir A, Gersh BJ, Shen WK, Hammill SC, Packer DL and Olson TM: Familial atrial fibrillation is a genetically heterogeneous disorder. J Am Coll Cardiol 41: 2185-2192, 2003

33. Nemer M: Genetic insights into normal and abnormal heart development. Cardiovasc Pathol 17: 48-54, 2008.

34. Bruneau BG: The developmental genetics of congenital heart disease. Nature 451: 943-948, 2008.

35. Pikkarainen S, Tokola H, Kerkelä R and Ruskoaho H: GATA transcription factors in the developing and adult heart. Cardiovasc Res 63: 196-207, 2004.

36. Katoh M and Katoh M: Integrative genomic analyses of WNT11: Transcriptional mechanisms based on canonical WNT signals and GATA transcription factors signaling. Int J Mol Med 24: 247-251, 2009.

37. Hu DL, Chen FK, Liu YQ, Sheng YH, Yang R, Kong XQ, Cao KJ, Gu HT and Qian LM: GATA-4 promotes the differentiation of P19 cells into cardiac myocytes. Int J Mol Med 26: 365-372, 2010.

38. White RA, Dowler LL, Pasztor LM, Gatson LL, Adkison LR, Angeloni SV and Wilson DB: Assignment of the transcription factor GATA4 gene to human chromosome 8 and mouse chromosome 14: Gata4 is a candidate gene for Ds (disorganization). Genomics 27: 20-26, 1995

39. Maitra M, Schluterman MK, Nichols HA, Richardson JA, Lo CW, Srivastava D and Garg V: Interaction of Gata4 and Gata6 with Tbx 5 is critical for normal cardiac development. Dev Biol 326: 368-377, 2009.

40. Pu WT, Ishiwata T, Juraszek AL, Ma Q and Izumo S: GATA4 is a dosage-sensitive regulator of cardiac morphogenesis. Dev Biol 275: 235-244, 2004.

41. Watt AJ, Battle MA, Li J and Duncan SA: GATA4 is essential for formation of the proepicardium and regulates cardiogenesis. Proc Natl Acad Sci USA 101: 12573-12578, 2004.

42. Garg V, Kathiriya IS, Barnes R, Schluterman MK, King IN, Butler CA, Rothrock CR, Eapen RS, Hirayama-Yamada K, Joo K, Matsuoka R, Cohen JC and Srivastava D: GATA4 mutations cause human congenital heart defects and reveal an interaction with TBX5. Nature 424: 443-447, 2003.

43. Chen Y, Mao J, Sun Y, Zhang Q, Cheng HB, Yan WH, Choy KW and Li H: A novel mutation of GATA4 in a familial atrial septal defect. Clin Chim Acta 411: 1741-1745, 2010.

44. Liu XY, Wang J, Zheng JH, Bai K, Liu ZM, Wang XZ, Liu X, Fang WY and Yang YQ: Involvement of a novel GATA4 mutation in atrial septal defects. Int J Mol Med 28: 17-23, 2011.

45. Wang J, Fang M, Liu XY, Xin YF, Liu ZM, Chen XZ, Wang XZ, Fang WY, Liu X and Yang YQ: A novel GATA4 mutation responsible for congenital ventricular septal defects. Int J Mol Med 28: 557-564, 2011. 
46. Nemer G, Fadlalah F, Usta J, Nemer M, Dbaibo G, Obeid M and Bitar F: A novel mutation in the GATA4 gene in patients with Tetralogy of Fallot. Hum Mutat 27: 293-294, 2006.

47. Rajagopal SK, Ma Q, Obler D, Shen J, Manichaikul A, TomitaMitchell A, Boardman K, Briggs C, Garg V, Srivastava D Goldmuntz E, Broman KW, Benson DW, Smoot LB and Pu WT: Spectrum of heart disease associated with murine and human GATA4 mutation. J Mol Cell Cardiol 43: 677-685, 2007.

48. Posch MG, Boldt LH, Polotzki M, Richter S, Rolf S, Perrot A, Dietz R, Ozcelik C and Haverkamp W: Mutations in the cardiac transcription factor GATA4 in patients with lone atrial fibrillation. Eur J Med Genet 53: 201-203, 2010.

49. Brewer A and Pizzey J: GATA factors in vertebrate heart development and disease. Expert Rev Mol Med 8: 1-20, 2006.

50. Posch MG, Perrot A, Berger F and Ozcelik C: Molecular genetics of congenital atrial septal defects. Clin Res Cardiol 99: 137-147, 2010.

51. Shiojima I, Komuro I, Oka T, Hiroi Y, Mizuno T, Takimoto E, Monzen K, Aikawa R, Akazawa H, Yamazaki T, Kudoh S and Yazaki Y: Context-dependent transcriptional cooperation mediated by cardiac transcription factors $\mathrm{Csx} / \mathrm{Nkx} 2.5$ and GATA-4. J Biol Chem 274: 8231-8239, 1999.

52. Mommersteeg MT, Brown NA, Prall OW, de Gier-de Vries C, Harvey RP, Moorman AF and Christoffels VM: Pitx2c and Nkx2-5 are required for the formation and identity of the pulmonary myocardium. Circ Res 101: 902-909, 2007.

53. Zhu W, Shiojima I, Hiroi Y, Zou Y, Akazawa H, Mizukami M, Toko H, Yazaki Y, Nagai R and Komuro I: Functional analyses of three $\mathrm{Csx} / \mathrm{Nkx}-2.5$ mutations that cause human congenital heart disease. J Biol Chem 275: 35291-35296, 2000.

54. Haïssaguerre M, Jaïs P, Shah DC, Takahashi A, Hocini M, Quiniou G, Garrigue S, Le Mouroux A, Le Métayer P and Clémenty J: Spontaneous initiation of atrial fibrillation by ectopic beats originating in the pulmonary veins. N Engl J Med 339 659-666, 1998.
55. Nattel S: Basic electrophysiology of the pulmonary veins and their role in atrial fibrillation: precipitators, perpetuators, and perplexers. J Cardiovasc Electrophysiol 14: 1372-1375, 2003.

56. Mommersteeg MT, Hoogaars WM, Prall OW, de Gier-de Vries C, Wiese C, Clout DE, Papaioannou VE, Brown NA, Harvey RP, Moorman AF and Christoffels VM: Molecular pathway for the localized formation of the sinoatrial node. Circ Res 100: 354-362, 2007.

57. Gutierrez-Roelens I, De Roy L, Ovaert C, Sluysmans T, Devriendt K, Brunner HG and Vikkula M: A novel CSX/NKX2-5 mutation causes autosomal-dominant AV block: are atrial fibrillation and syncopes part of the phenotype? Eur J Hum Genet 14: 1313-1316, 2006

58. Watanabe $\mathrm{Y}$, Benson DW, Yano S, Akagi T, Yoshino M and Murray JC: Two novel frameshift mutations in NKX2.5 result in novel features including visceral inversus and sinus venosus type ASD. J Med Genet 39: 807-811, 2002.

59. Pabst S, Wollnik B, Rohmann E, Hintz Y, Glänzer K, Vetter H, Nickenig $G$ and Grohé $C$ : A novel stop mutation truncating critical regions of the cardiac transcription factor NKX2-5 in a large family with autosomal-dominant inherited congenital heart disease. Clin Res Cardiol 97: 39-42, 2008.

60. Gruver EJ, Fatkin D, Dodds GA, Kisslo J, Maron BJ, Seidman JG and Seidman CE: Familial hypertrophic cardiomyopathy and atrial fibrillation caused by Arg663His beta-cardiac myosin heavy chain mutation. Am J Cardiol 83: 13H-18H, 1999. 